\title{
Alfabetització biotecnològica: molt més que una història de gens
}

\author{
Ángel González Benito, Maite Novo Molinero \\ Grup FORTE, Institut de Ciències de l'Educació. Universitat Rovira i Virgili \\ mteresa.novo@urv.cat
}

Resum: La biotecnologia moderna (la genòmica $i$ les seves tecnologies associades) s'està desenvolupant a una velocitat vertiginosa, tant en la recerca bàsica com en les seves aplicacions tecnològiques (de la medicina a l'agricultura). A la nostra societat, la biotecnologia cada cop exercirà un major impacte, i es requeriran ciutadans informats $i$ crítics capaços de prendre decisions sobre aspectes biotecnologics. Aquest article reflexiona al voltant de la necessitat d'alfabetitzar biotecnològicament en les etapes formatives obligatòries.

Paraules clau: biotecnologia, actitud, ciència-tecnologia-societat.

Abstract: Modern biotechnology (the genome and its associated technologies) is developing at breakneck speed, both in terms of basic research and its technological applications (from medicine to agriculture). In modern society, biotechnology exerts an increasingly important impact which will require critically informed citizens capable of taking decisions regarding biotechnological issues. This article reflects on the need to increase biotechnological literacy during compulsory education.

Key words: biotechnology, attitude, sciencetechnology-society.

\section{El context biotecnològic}

A les últimes dècades, s'ha produit una important revolució en el camp de la recerca i l'estudi de la biologia. La genòmica i les seves tecnologies associades (o biotecnologia moderna) tenen tot el potencial per esdevenir una de les revolucions científiques i tecnològiques més importants del segle Xxi (Kirkpatrick, Orvis i Pittendrigh, 2002). S'han desenvolupat noves tècniques que permeten tant la seqüenciació de genomes com les anàlisis, a escala global, d'aquests genomes en diferents nivells biològics (gen, mRNA, proteïnes, etc), cosa que ha originat un nou terme anomenat "omics", que engloba tots aquests àmbits d'estudi (genòmics, transcriptòmics, proteòmics, metabolòmics, etc). Les aplicacions de la biotecnologia moderna són extenses i van des de la recerca biomèdica (teràpia gènica, predisposicions genètiques a malalties, millora de diagnòstics, aliments funcionals, etc.) fins a l'agricultura (bioenergètica, transgènics, etc.).

La biotecnologia no és, però, una ciència de "nova generació". Aquesta es pot definir com l'ús d'organismes, components o sistemes biològics per obtenir béns i serveis. Tenint en compte, doncs, aquesta definició, podem afirmar que la biotecnologia ha estat utilitzada des de fa milers d'anys - això sí, d’una forma empírica; és a dir, sense base científica. 
Ja en el neolític es van domesticar animals i plantes. La civilització sumèria i la babilònica (6000 a. de C.) elaboraven cervesa (fermentació amb llevats) i els egipcis (4000 a. de C.) pa de blat. Altres productes biotecnològics fabricats de manera empírica des de l'antiguitat són el formatge, les begudes fermentades com ara el iogurt o la soja, i el tractament d'aigües residuals.

No es pot parlar de biotecnologia com a ciència fins al segle XIX; però existeixen diversos avenços científics i tècnics que n’assenten les bases. Alguns d’aquests avenços són: la invenció del microscopi (Van Leeuwenhoek i Hook, s. XVII) i, al voltant del 1860, la fonamental aportació del científic Louis Pasteur: descobrir que les fermentacions les realitzen microorganismes. Ja en el segle XIX, el desenvolupament tecnològic permet millorar les tècniques de microscòpia, així com desenvolupar les tècniques d'asèpsia, esterilització i pasteurització, la qual cosa facilitarà aconseguir cultius de soques microbianes pures (sense barreges de microorganismes), fita fonamental per estudiar en profunditat els bacteris i els organismes unicel-lulars.

Gràcies a tots aquests esdeveniments i a l'esforç científic i a una contínua millora tecnològi$\mathrm{ca}$, avui en dia podem parlar de plantes resistents a plagues, d'enzims per a detergents que generen menys contaminants, de retardar la caducitat dels aliments o de la producció de medicaments (antibiòtics).

El 2010, la Comissió Europea va iniciar el projecte Europe 2020 Strategy, dissenyat per ajudar la Unió Europea (UE) a sortir enfortida de l'actual crisi financera i econòmica, i per preparar-la per als reptes que vindran en les properes dècades. La idea és estimular el creixement econòmic, crear més i millors llocs de treball i desenvolupar una economia més ecològica i basada en la innovació. La biotecnologia es veu com la major força motriu en els camps de la salut i el benestar dels ciutadans europeus. En els darrers

¿Creus que la biotecnologia i l'enginyeria genètica tindran un efecte positiu,

negatiu o no en tindran cap en la teva manera de viure d’aquí a 20 anys?

\begin{tabular}{lcccc} 
& Efecte positiu & Efecte negatiu & Cap efecte & NS/NC \\
EU 27 & $53 \%$ & $20 \%$ & $7 \%$ & $20 \%$ \\
Sexe & & & & \\
Homes & $58 \%$ & $18 \%$ & $8 \%$ & $16 \%$ \\
Dones & $48 \%$ & $21 \%$ & $7 \%$ & $24 \%$ \\
\hline Educació (edat a la fi dels estudis) & & & & \\
$15-$ & $42 \%$ & $18 \%$ & $7 \%$ & $20 \%$ \\
$16-19$ & $52 \%$ & $21 \%$ & $7 \%$ & $12 \%$ \\
$20+$ & $62 \%$ & $19 \%$ & $6 \%$ & $15 \%$ \\
Encara estudien & $61 \%$ & $19 \%$ & & \\
Ús d'internet & & & $7 \%$ & $14 \%$ \\
Tots els dies & $60 \%$ & $19 \%$ & $8 \%$ & $29 \%$ \\
A vegades & $53 \%$ & $20 \%$ & $8 \%$ & $17 \%$ \\
Mai & $44 \%$ & $19 \%$ & $7 \%$ & $24 \%$ \\
\hline Educació en ciència/tecnologia & & $19 \%$ & $8 \%$ & \\
Sí & $57 \%$ & $20 \%$ & & \\
No & $48 \%$ & & & \\
\hline
\end{tabular}

Taula que mostra els resultats de l'enquesta, publicada a l'Eurobaròmetre 341 (2010), sobre l'optimisme dels ciutadans europeus vers la biotecnologia i l'enginyeria genètica. 
anys, la UE ha incentivat iniciatives encaminades a estimular i coordinar el desenvolupament biotecnològic. Tot i que Europa està fortament basada en aspectes químics i agrícoles, temes com ara la protecció del mediambient, la seguretat del consumidor, la presència de forts moviments ecologistes i la poca acceptació social han estat identificats com a factors clau que afecten el desenvolupament biotecnològic global (Special Eurobarometer 341, 2010).

\section{Actitud vers el desenvolupament biotecnològic}

El recent desenvolupament de la biotecnologia moderna i l'enginyeria genètica ha provocat un gran abisme entre allò que la comunitat científica entén com a risc i benefici i el que entén el públic en general. A més, els productes que s'han introduit al mercat han estat obstaculitzats, amb una resistència gairebé universal, pel públic, que no ha accepta els arguments de les companyies productores, probablement perquè aquests arguments no han estat entesos amb profunditat $\mathrm{o}$, fins i tot, perquè ni tan sols s'han volgut escoltar (Special Eurobarometer 341, 2010). En un qüestionari efectuat en làmbit europeu sobre la percepció dels ciutadans sobre la biotecnologia, s'hi observa que hi ha una estreta majoria d'europeus (53\%) que veuen la biotecnologia i l'enginyeria genètica positivament. Una dada interessant és que hi ha una gran quantitat de persones (20\%) que no té cap tipus d’opinió, i augmenta el percentatge en els col-lectius socials que tenen menys formació (32\%) i que menys utilitzen les noves tecnologies (29\%).

A la societat actual, la ciència i la tecnologia són eixos fonamentals que condicionen el dia a dia de tots els ciutadans. És important que el públic comprengui els conceptes bàsics que conformen la biotecnologia moderna. I és especialment important que els comprenguin els joves actuals, perquè els necessitaran, com a membres d'una societat caracteritzada per canvis ràpids, en les seves futures carreres i en el seu dia a dia, per tal de prendre decisions personals i socials sobre temes relacionats amb la ciència i la tecnologia. En aquest sentit, la didàctica de les ciències hauria de contribuir que la societat en general (mitjançant l'actuació del professorat de ciències, entre d’altres) conegués els principals conceptes de la biotecnologia moderna, a fi de capacitar la societat a prendre decisions conscients sobre temes relacionats amb la biotecnologia. La societat hauria de poder respondre qüestions com ara: ¿El iogurt és un producte biotecnològic? ¿Una bona higiene ajuda a prevenir malalties genètiques? ¿Només quan mengem un aliment transgènic ingerim gens?

\section{Perspectives de futur}

En aquest segle XxI, la didàctica de les ciències no té sentit, si no aproximem la ciència i la tecnologia al seu context social. Nombrosos especialistes en didàctica de les ciències de tot el món promouen, com a finalitat central de l'ensenyament de les ciències, l'alfabetització científica i tecnològica de tots els ciutadans: pretenen desenvolupar el coneixement $i$ els hàbits mentals necessaris perquè puguin arribar a ser persones responsables, capaces de pensar per si mateixes, dins d'una societat cada cop més complexa i dependent de la tecnologia (Dimopoulos i Koulaidis, 2003; Jenkins, 1997; Miller, 1998). Aquesta és una de les finalitats de l'enfocament STSE (Ciència, Tecnologia, Societat i Ambient), en el seu propòsit de millorar l'ensenyament de les ciències i innovar-lo. Lessència del paper de l'enfocament STSE en l'educació científica és sobretot educar per aconseguir la participació cívica en les decisions tecnocientífiques. Leducació tecnocientífica ha de permetre, als ciutadans, no tan sols conèixer els processos, analitzar-los, valorar-los i utilitzar els artefactes del món que els envolta, sinó que ha d'integrar estratègies per al desenvolupament d'aptituds i actituds participatives i obertes al diàleg, la negociació i la presa de decisions en relació amb els problemes associats al desenvolupament científic i tècnic (Jenkins, 2002; Manassero, Vázquez i Acevedo, 2001; Lee i Roth, 2002; Martín i Osorio, 2003, Martín, 2005). Una de les qüestions fonamentals rau en com es pot potenciar i desenvolupar l'alfabetització científica mitjançant la didàctica de les ciències. Diferents estudis fets en aquest àmbit apunten a una perspectiva social constructivista de l'aprenentatge com a millor enfoca- 
ment per a l'alfabetització científica (Freedman, 1997; Bennett, 2001). Aprendre esdevé el procés d'ajustar models mentals per acomodar noves experiències, i no és únicament rebre i integrar la nova informació que el professor ha presentat (Driver, Asoko, Leach, Mortimer i Scott, 1994). Laprenentatge constructivista atribueix un paper fonamental al context social i cultural dels alumnes, per entendre què succeeix a la societat i poder construir coneixement a partir d'aquesta comprensió.

Ensenyar biotecnologia a la societat i/o alfabetitzar-la des d'una perspectiva biotecnològica ha despertat, durant els darrers anys, un gran interès en la comunitat científica de l'àmbit educatiu. El primer camp on s'ha començat a investigar és en les actituds vers la biotecnologia moderna i els interessos amb què parteixen tant estudiants com professors. Nombrosos estudis fets en diferents països s'han centrat a avaluar i analitzar les actituds dels alumnes i professors vers diferents aspectes de la biotecnologia, incloent-hi els coneixements previs, les pors, les creences i els temes ètics relacionats amb l'ús d'aquestes noves tecnologies (Klop i Severiens, 2007; Steele i Aubusson, 2004; Kidman, 2009; Lamanauskas i Makarskaité, 2008). Aquests estudis parteixen amb un objectiu comú: analitzar quins són els aspectes que s'han de considerar en els plans curriculars, a fi d'incorporar l'alfabetització científica al currículum de ciències. Hi ha estudis que han remarcat que l'educació científica -i, en particular, l'educació sobre la biotecnologia moderna- no tan sols s'ha de focalitzar en el coneixement i la comprensió, sinó que també ha de considerar el component afectiu, ja que treballant-lo ajudarem els estudiants a crear una actitud més equilibrada respecte a la biotecnologia i les seves implicacions (Klop i Severiens, 2007). També s'ha observat que els estudiants tenen actituds molt positives respecte a l'estudi de la biotecnologia, sempre que els temes tractats impliquin aspectes personals dels alumnes. Sorprenentment, s'ha observat que als professors els interessa menys que als alumnes l'ensenyament de la biotecnologia moderna (Steele i Aubusson, 2004; Kidman, 2009).

Grups de científics han iniciat debats amb altres comunitats, per tal de tractar els aspec- tes ètics i legals, i les implicacions socials, que comporten la ciència i la tecnologia. La idea és donar veu al públic perquè la societat s'impliqui en la presa de decisions sobre temes científics i tecnològics, donant lloc a camins socialment viables per a la innovació científica. ¿Quin tipus de societat volem?, i ¿com ens pot ajudar a aconseguir-la, la nova tecnologia? Aquestes qüestions són sobre aspectes ètics i valors socials que la ciència per si mateixa no pot respondre. El públic espera i vol que la ciència i la tecnologia resolgui els problemes, i alhora vol decidir quins són els problemes que cal resoldre. Els ciutadans s'han de veure com a participants actius en temes de política científica, i amb ells caldria compartir la visió de la ciència socialment viable; d’aquesta manera, s'aconseguiria la innovació tecnològica (Gaskell, Einsiedel, Hallman, Horning-Priest, Jackson i Olsthoorn, 2005). Per tal d'aconseguir aquesta societat implicada a prendre decisions sobre política científica, cal una ciutadania formada i capaç de decidir conscientment d'acord amb les evidències científiques, combinades amb consideracions ètiques i morals. Així, doncs, la societat hauria de tenir les bases per poder opinar de manera raonada sobre si cal usar transgènics tant en la medicina com en l'alimentació, sobre com s'haurien d'etiquetar aquests productes, etc. En resum, la societat ha de ser capaç de prendre decisions basades en el coneixement, $\mathrm{i}$ aquest coneixement ha de ser de qualitat, independentment de l'àmbit personal, ja que la biotecnologia, com ja s'ha comentat, actualment forma una part indissoluble de la nostra societat i del nostre dia a dia.

\section{Bibliografia}

Bennett, J. (2001). "Science with attitude: the perennial issue of pupils' responses to science". School Science Review, 82, pàg. 59-67.

Dimopoulos, K., i Koulaidis, V. (2003). "Science and technology education for citizenship: The potential role of the press". Science Education, 87, 2, pàg. 241-256.

Driver, R.; Asoko, H.; Leach, J.; Mortimer, E., i Scotт, P. (1994). "Constructing scientific knowledge in the classroom". Educational Researcher, 23, 7, pàg. 5-12. 
European Comission (2010). Special Eurobarometer 341. "Biotechnology", <http:// ec.europa.eu/public_opinion/archives/ebs/ ebs_341_en.pdf> [consulta: 20-06-2011].

Freedman, M. P. (1997): "Relationship among laboratory instruction, attitude toward science, and achievement in science knowledge". Journal of Research in Science Teaching, 34, 4, pàg. 343-357.

Gaskell, G.; Einsiedel, E.; Hallman, W.; Horning-Priest, S.; Jackson, J., i Olsthoorn, J. (2005). "Social values and the governance of science". Science, 310, pàg. 1908-1909.

Jenkins, E. W. (1997). “Towards a functional public understanding of science". Science Today. Londres: Routledge.

- (2002). "Linking school science education with action". Dins W. M. Roth i J. DÉsAultels (ed.), Science Education as/for Sociopolitical Action. Nova York: Peter Lang.

Kidman, G. (2009). "Attitudes and interests towards biotechnology: the mismatch between students and teachers". Eurasian Journal of Mathematics, Science and Technology Education, 5, 2, pàg. 135-143.

Kirkpatrick, G.; Orvis, K., i Pittendrigh, B. (2002). "GAME: A teaching model for biotechnology". Journal of Biological Education, 37, 1, pàg. 31-35.

Klop, T., i Severiens, S. (2007). "An exploration of attitudes towards modern biotechnology: a study among Dutch secondary school students". International Journal of Science Education, 29, 5 pàg. 663-679.

Lamanauskas, V., i Makarskaité, R. (2008). "Lithuanian university student's knowledge of biotechnology and their attitudes of the taught subject". Eurasian Journal of Mathematics, Science and Technology Education, 4, 3, pàg. 269-277.

LeE, S., i Roth, W. M. (2002). "Learning science in the community". W. M. Roth i J. DÉsaultels (ed.), Science Education as/for Sociopolitical Action. Nova York: Peter Lang.

Manassero, M. A.; Vázquez, A., i Acevedo, J. A. (2001). Avaluació dels temes de ciència, tecnologia i societat. Palma de Mallorca: Conselleria d'Educació i Cultura del Govern de les Illes Balears.

Martín, M., i Osorio, C. (2003). "Educar para participar en ciencia y tecnología. Un proyecto para la difusión de la cultura científica”. Revista Iberoamericana de Educación, 32, pàg. 165-210.

Martín, M. (2005). "Cultura científica y participación ciudadana: materiales para la educación CTS”. Revista Iberoamericana de Ciencia, Tecnología y Sociedad, 6, 2, pàg. 123-135.

Miller, J. D. (1998). “The measurement of civic scientific literacy”. Public Understanding of Science, 7, 3, pàg. 203-223.

Steele, F., i Aubusson, P. (2004). "The challenge in teaching biotechnology". Research in Science Education, 34, pàg. 365-387. 